\title{
EVALUATING THE EFFECTIVENESS OF THE JOB HAZARD ANALYSIS AND RISK ASSESSMENT REPORTS FOR BUILDING SERVICES INSTALLATION
}

\author{
Gino Hosein ${ }^{1 *}$ and Indrajit Ray ${ }^{2}$ \\ ${ }^{1,2}$ Faculty of Engineering, The University of the West Indies, Trinidad \\ ${ }^{1}$ Email: ginohosein@yahoo.co.uk*(Corresponding author) \\ ${ }^{2}$ Email: IndrajitRay29@gmail.com
}

\begin{abstract}
Excavating and backfilling trenches along the roadway to accommodate the installation of building services are common to the local industry. These services include electricity, water, telecommunications and data. The job hazard analysis (JHA) and risk assessment (RA) documents are typical forms prepared before the execution of these works to ensure health and safety. However, due to the hazards associated with the works, there are cost impacts which almost always affect the labour, materials and equipment resources. The main reasons for these are scope creep and the unforeseen nature of what to expect when breaking ground. This results in either the client or the contractor absorbing the additional unforeseen expenditure. The purpose of this research is to improve the efficiency of preparing and administering JHA and RA documents to help reduce unforeseen expenditures. This includes identifying and analysing all typical hazards and risks associated with labour, materials and equipment and the respective potential cost impacts. The data was collected by means of a population survey and validation of the results was achieved by means of a case study analysis of typical projects. The results revealed the main hazards associated with JHA and RA. It also identified some of the barriers to implementation such as lack of specific training, the need for more academic research, the use of more technology and for regulatory authorities to be more proactive. It was recommended that further research into this topic be done.
\end{abstract}

Keywords: Building services, Cost impact, JHA, RA.

https://doi.org/10.47412/CDOQ2845

\section{Introduction}

\subsection{Background}

Having proper documentation to execute works in a safe and effective way is one of the main objectives of civil works associated with building services installation. There are several tools that can be used to achieve this objective, however the choice of which is based on the nature of the project and the players involved; mainly the client and the contractor.

One such tool is the risk assessment (RA) and by extension the job hazard analysis (JHA). However, current risk assessment tools do not capture the risks specific to construction sites, because they only focus on assessing identified risks from a predefined hierarchy of events [1]. This is especially challenging to the construction sector as each project is unique [17]. The use of effective site personnel to execute the works is also of great importance. In most cases, these professionals are the construction manager and the construction superintendents. Their ability to 
recognise risks and hazards is an essential skill to construction sites [2]. This comes with specific training along with a blend of experience and academic qualifications. Professionals are generally prone to heavily rely on their own experiences and knowledge on decision making with respect to risk assessment. This lack of a systematic approach negates ways of checking the reliability of their decisions [3]. One way of dealing with this is to have a realistic risk assessment tool. Obtaining a realistic project risk assessment demands an effective mechanism for aggregating individual risk assessments [4]. This is a major gap identified in the local construction industry. Relating to risk assessments, it was identified a listing of relevant causes affecting safety performance in the construction industry [5]. The summary of this listing was related to three main causes; labour, material and equipment. Specific to the civil works associated with building services installation locally, these three main causes can be used as well.

Based on this background, the research encompasses surveying of a sample population followed by data analysis to determine the effectiveness of the JHA and RA reports for civil works associated with building services installation locally. The Uff report identified these documents among others comprising the project management sphere as not being effective locally [6]. The report highlighted the fact that malpractices and bad methods were being used in the local construction industry.

\subsection{Research Focus}

The aim of the research is to improve the awareness of safety project delivery cost impacts in civil works associated with building services installation, by identifying the effectiveness of the JHA and RA documents.

The objectives are listed as follows:

- To identify the main hazards in the JHA and RA building services installation.

- To assess the cost impacts of the labour, materials and equipment resources with these hazards.

- To evaluate the main barriers faced with JHA and RA implementation.

The research question asks what are the main barriers in the implementation of the JHA and RA and their association with the cost impacts of the labour, materials and equipment resources associated with building services installation?

\section{Literature Review}

Because of the vast existing amount of knowledge in this topic, there are obvious overlaps in each section. However most of the knowledge is varied. After careful analysis of the existing literature, it can be classed into two main categories:

- The Qualitative Approach

- The Quantitative Approach

\subsection{The Qualitative Approach}

Risk perception is presently viewed as a project attribute rather than an estimation variance. It was written that risk assessment has traditionally focussed on quantitative methods. But they should also include for individual knowledge, experience, intuitive judgement and general rules of thumb. Further to this risk cost should be used as a practical measure of risk impact [4]. However, no 
research was presented into the practical application of a quantitative and qualitative approach to the obtaining risk cost. This will be done in this research to identify the impacts of cost on labour, materials and equipment. Further to this the construction industry has been identified as one with a high risk of injuries, illnesses and fatalities. One qualitative method of risk assessment is effective tailgate talks, however ineffective ones can be useless [7].

It was also deduced that the construction industry has risky situations and poor working conditions [5]. They went on to state that the risk assessment is the first step to achieving safety. This can be specifically refined to decision making in safety programs. It was stated that the information gathered for risk assessments is often plagued by uncertainties. This often weakens the risk analysis. Checklists can be used, however there is difficulty in obtaining a comprehensive listing as all sites are unique. This can be deduced for the local construction industry as well. No checklist was developed by the researchers.

However, this research will focus on the use of a comprehensive checklist specific for civil works associated with building services installation currently used in the local industry by a Government agency, the Trinidad and Tobago Electricity Commission (TTEC). The main hazards identified were 1).the physical environment, 2).gravity, 3).kinetic/vehicular, 4).chemical, 5).body mechanics, 6).electricity, 7).noise, 8).mechanical, 9).biological and 10).other. These will be elaborated on more in the sample population survey questionnaire.

In the construction sector, each site is considered a unique workplace [1]. Because of this, risks and hazards are specific to each site as well. This is applicable to this research. However, current practices only allow for selection of these risks and hazards from a predefined list. This is one limitation identified about the qualitative approach.

However, there are some overlapping risks. Hazards and risks on construction sites are common [3]. However, construction professionals mainly rely on their own experiences and knowledge on decision making and risk assessment. This is a common trend throughout the local construction industry as well. There have been various methodologies and technologies to improve worker safety on construction sites. Research has been carried out on work processes thus far, but not much has been done on individual workers performance [8]. This is important as, for certain tasks, OSHA requires safety competent workers. It was identified that the construction sector is one of the most hazardous work places worldwide [9]. They stated that hazard assessment is the most important tool in safety management.

\subsection{The Quantitative Approach}

The safety risk assessment is a foundation which forms part of safety management [3]. However, this is only effective as the delegated "safety" professional's perception and understanding of safety risks. This is an environment that is hazardous, quick changing and highly dynamic. The need for a systematic risk assessment was highlighted. A risk assessment model was introduced to alleviate this problem. And a case study was carried out to prove the reliability and workability of it. This model is applicable to risks associated with specific trades. This is the limitation as construction works, for this research, are dynamic and it is very difficult to predict all of the trades required. Therefore this model is not applicable to this research. Researchers highlighted the importance of risk/hazard analysis leading to reduced costs [10]. They used a risk impact rating for costs of high, medium and low. This will be used in this research. Construction safety management activities are dependent on hazard identification and communication [11]. In practice 
however, significant hazards are not identified and communicated with the workforce. This is the gap the researchers identified. A model to negate this gap was proposed, it was the hazard identification and transmission (HIT). The model attempts to bridge the gap between work hazards imagined versus actual work hazards. One limitation is that it is not applicable to small projects. Therefore it is not applicable for this research. It was contended that valuable information can be gotten by actually reconstructing the scenarios of accidents [1]. This gives real time information. Software is available for this. Occupation risk model (ORM) developed by the Dutch Workgroup Occupational Risk Model (WORM), is one important example of this. Unlike works by these authors, this current research can rely on historical data from similar projects executed before. The limitation of this research is that it is applicable for a European environment. Further works will have to be carried out to modify it to the Caribbean environment. Construction operations are associated with a high level of risk. They wrote that the injury rate in the US, in 2016, was 10 which is significantly higher than the national injury rate [12]. Their main argument was that virtual reality is recommended to be used. It has the potential for safety performance improvement. Similar to BIM technologies, this can be used in the same way. Augmented reality is also proposed. An example used was "smart" helmets which give real-time data such as workplace conditions e.g. temperature etc. This also provides the location of all employees on the site which is useful in an emergency. This is a recommendation that can be made to the local construction industry, however more research needs to be carried out. The authors proposed that technology can bring many benefits to the safety aspect of the construction industry. No research into the actual technology impacts was done.

The researcher's main argument was that most research use the probability approach of hazard identification which is subjective and relies on historical data [9]. However, their study proposes possibility (fuzzy) approach. This takes into account judgements and perceptions of professionals. This relates to the article by earlier about the need to have a mixed methods approach to risk assessment [4].

One limitation of the probability method is a as a result of poor record keeping and lack of past information. This is also the case with the local construction industry as included in the Uff report [6]. This study also used a limited sample size. The findings will be compared with findings of this research.

Construction professionals', mainly the construction managers and superintendents, ability to perceive risks are an important skill on construction sites [2]. However, most hazards and risks are gotten from textbooks or guidelines. It was further stated that research carried out by [13], found that only $6.7 \%$ of the method statements in the UK identified all relevant hazards and risks. One reason for this was because of the unplanned conditions because of the lack of regular work. This is applicable for this research as well because most emergency works only get executed on the weekend and often times by different contractors. The research was about getting data from a specific sample population. A virtual reality test was done for some of the respondents. Others were tested with a traditional test which consisted of a photograph of a typical construction site. All were asked to list the hazards they identified.

\subsection{Limitations of the Current Research}

One common theme is that the construction industry is a unique place for risk assessment. This is because each work site is considered separate and although there are some overlaps in risks, the physical conditions are an important consideration and this contributes to the uniqueness of each 
project as there will never be the same labour, materials and equipment resources used in any two projects. Another commonality is that there should be emphasis placed on the training and safety knowledge of individuals charged with the responsibilities of administering JHA and RA on sites. These individuals are mainly the construction manager and the site superintendent. Articles mentioned the cost impacts, but no research was done into the actual impacts.

In conclusion there are a few articles that considers the cost impacts of the risks, but none evaluates the cost impact of labour, materials and equipment separately in relation to civil works associated with building services installation. This is the gap identified in the literature review.

\section{Research Methodology}

In order to achieve the objectives of the research, a literature review was carried out first via a desktop study of peer reviewed articles. Next a survey questionnaire encompassing the likert scale was administered to a sample survey population. The sample size was determined via the Kish Equation [18] by using a population of 150, the minimum required survey participants calculated was 47 . In order to achieve the minimum 47, 100 surveys were administered. From the survey results 50 responses were usable of which 30 were contractors' employees and 20 were employees from the client. A pilot study was carried out before the actual survey on five individuals to ascertain the effectiveness of the actual survey. Those who undertook the trial survey were randomly chosen and were not asked to participate in the actual survey to avoid biasness. The questionnaire consisted of two sections. Section one questioned the respondents on general information. This section consisted of seven questions. Section two questioned the respondents on topics relating to the impact of cost on labour, materials and equipment. This section was eleven questions. Finally the research was validated by means of a case study on three construction sites applicable to the research. 
The objectives were achieved in Fig.1:

\section{Stage 1}

Objective 1: To identify the main hazards in the JHA and RA associated with civil works associated with building services installation.

Method of research - Desktop study literature review.

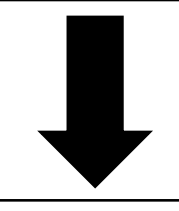

Stage 2

Objective 2: To assess the cost impacts of the labour, materials and equipment resources with these hazards.

Method of research - Sample population survey questionnaire.

\begin{tabular}{l} 
Stage 3 \\
Objective 3: To evaluate the main barriers \\
faced with JHA and RA implementation. \\
$\begin{array}{l}\text { Method of research }- \text { Findings and } \\
\text { discussion. }\end{array}$ \\
\hline
\end{tabular}

Figure 1: Research methods flow

\section{Findings and Discussion}

\subsection{Objective 1: To identify the Main Hazards in the JHA and RA Associated with Civil} Works Associated with Building Services Installation

As outlined in figure 1, this objective was achieved via the desktop literature review. The hazards identified from existing literature presently used in the industry JHA and RA documents are:

- Physical Environment - E.g. Uneven ground, limited workspace, poor housekeeping etc.

- Gravity - E.g. Falling from heights, falling objects, falling structures and climbing obstruction.

- Kinetic/Vehicular - E.g. Fast/slow moving traffic, driving conditions, moving loads etc.

- Chemical - E.g. Confined spaces, toxic or poisonous, corrosive etc. 
- Body Mechanics - E.g. Slips/trips, lifting/twisting strains, repetitive strains etc.

- Electricity - Eg. Live apparatus, induction/back feed, static charge etc.

- Noise - E.g. Chronic >80dB, explosive and distraction levels.

- Mechanical - E.g. Equipment failure, flying objects, tension loads, struck by etc.

- Biological - E.g. Hazard to pedestrians, dogs, bees, snake etc.

- Other - E.g. Hot objects, poor illumination, lacerations, violence, other utilities etc.

\subsection{Objective 2: To Assess the Cost Impacts of The Labour, Materials and Equipment Resources with these Hazards}

The current situation locally:

Based on the general section of the sample population survey questionnaire, many points were deduced. The overall survey population was mainly skilled labourers who made up $46 \%$ of it. With the project engineers, site supervisors and assistant site supervisors making up the second most with $22 \%$. This is expected as supervision personnel will be less than the actual work force. $30 \%$ of the population worked in only civil projects, whereas the other $70 \%$ were classed as general construction. The same $30 \%$ represented the client while the $70 \%$ represented the contractor. This is not surprising as most contractors locally are expected to be general contractors, partly because of the lack of work in the construction industry at present. 54\% of the population had over 15 years' experience, this was a fairly even spread between the client and the contractor. Not surprisingly, $100 \%$ of the population had experience with JHA and RA in projects. However, only $76 \%$ believed that the JHA and RA forms were useful with respect to site safety. $14 \%$ were in disagreement and $10 \%$ were unsure. These results can be interpreted that, based on the sample survey population, there seems to be doubt about the JHA and RA forms in the daily operations of site works. One reason for this can be that locally there is no formal training for the use of these forms. It is based on the interpretation, knowledge and experience of the persons filling out the forms.

\section{The cost impacts of the hazards on labour, materials and equipment:}

The results analysed from the survey were mixed. With most of the cost impacts being rated as medium with the exception of electricity which was rated as a high cost impact. Biological, noise and chemical were the lowest ranked respectively, all with low cost impact ratings. The top three hazards identified as having the most impact on costs with respect to labour, materials and equipment were electricity, mechanical and body mechanics. Out of these labour and material averaged the same cost impact, 2.50, which was slightly higher than the 2.44 rating for equipment.

With respect to labour, it was not surprising that this was the average highest overall cost impact from the hazards. This is the most difficult resource to manage compared to material and equipment, because it involves the human factor. If workers are not entirely sure about what is expected of them on the job site in terms of safety, their will inevitable be delays in the execution of works. Further to this is the problem of not having anyone on site on both the client and contractor end that is completely sure. This is not only a local problem but an international one as well [2].

The hazard seen as having the largest impact on cost with respect to labour was electricity, whereas the lowest impact was noise. This can be seen in Table1. 
Table 1: Average Cost Impacts for Labour, Materials and Equipment of the Hazards

\begin{tabular}{|c|c|c|c|}
\hline Hazards & $\begin{array}{c}\text { Average Labour } \\
\text { Cost Impact }\end{array}$ & $\begin{array}{c}\text { Average Materials } \\
\text { Cost Impact }\end{array}$ & $\begin{array}{c}\text { Average Equipment } \\
\text { Cost Impact }\end{array}$ \\
\hline $\begin{array}{c}\text { Physical } \\
\text { Environment }\end{array}$ & 1.72 & 1.80 & 1.84 \\
\hline Gravity & 1.20 & 1.10 & 1.00 \\
\hline Kinetic/Vehicular & 1.70 & 1.70 & 1.78 \\
\hline Chemical & 1.40 & 1.70 & 1.51 \\
\hline Body Mechanics & 2.30 & 2.10 & 2.20 \\
\hline Electricity & 3.00 & 3.00 & 2.80 \\
\hline Noise & 1.10 & 1.10 & 1.71 \\
\hline Mechanical & 2.20 & 2.40 & 2.31 \\
\hline Biological & 1.40 & 1.30 & 1.20 \\
\hline Other & 2.00 & 1.80 & 2.02 \\
\hline
\end{tabular}

Materials was slightly the second rated in the average overall cost impacts for the hazards. The biggest issues for materials on construction sites are storage, handling and placement. Specific for civil works associated with building services, the main materials are red sand and crusherun. Both are required to be placed dry and have a California Bearing Ration (CBR) of at least 95\% after compaction as per specifications. It was not surprising that electricity, bodily mechanics and mechanical hazards had the top three cost impacts here respectively as seen in table 1 . Because those are the top three that can cause delays in the supply and placement of the materials resulting in additional costs. Noise, gravity and biological was the lowest rated cost impact on materials respectively.

The equipment rating was the lowest rated of the three. This was somewhat surprising as, equipment failure means that woks cannot be continued. However, based on local construction industry experience, mobilization and the performance of the equipment on the projects are the main hazards that impact costs. However, as per Table1, it can be seen that the mechanical hazards relating to the equipment was the second highest rated after electricity and before body mechanics.

Table 2: Average Cost Impacts of the Hazards

\begin{tabular}{|c|c|}
\hline Hazards & Average Cost Impacts \\
\hline $\begin{array}{c}\text { Physical } \\
\text { Environment }\end{array}$ & 1.79 \\
\hline Gravity & 1.10 \\
\hline Kinetic/Vehicular & 1.73 \\
\hline Chemical & 1.53 \\
\hline Body Mechanics & 2.20 \\
\hline Electricity & 2.93 \\
\hline Noise & 1.30 \\
\hline Mechanical & 2.30 \\
\hline Biological & 1.30 \\
\hline Other & 1.93 \\
\hline
\end{tabular}


Overall as seen in Table2, electricity, mechanical and body mechanics had the biggest impact on cost respectively. These results are not surprising.

\subsection{Objective 3: To Evaluate the Main Barriers Faced with JHA and RA Implementation}

\section{The main barriers for implementation of the JHA and RA:}

Based on the survey results. It can be assumed that most people associated with the delivery of civil works associated with building services from a safety point of view are lower level staff. Management, managers and supervisors, make up a small amount. Out of this lower level staff, the majority of the workers associated with the JHA and RA on a daily basis are skilled labourers. With little or no qualifications to work in these positions, this highlights the need for proper training. Researchers highlighted the major benefits of training over 1500 persons on the administration of proper tailgate talks in California, USA [7].

It can be deduced that actual onsite training is needed to deal with actual onsite hazards. Having to identify actual hazards on site in the JHA at the same time when labour, materials and equipment are mobilized, and are waiting for execution of works pending completion of the JHA, can prove challenging for the most experienced of people. This is when error occurs, training is needed to mitigate against this hazard. It was stated that research carried out, found that only $6.7 \%$ of the method statements in the UK identified all relevant hazards and risks [13]. It will be interesting to find out the level of accuracy locally. This leads to the next barrier, a lack of adequate research locally to overcome potential problems. We can only have reliable data with proper research methods and testing. There has been a lot of works done internationally but, based on the literature review, none of any significance has been found locally. Research has been focused on other areas deemed more important, but as discussed earlier there is a cost impact on incorrect administration of JHA and RA documents.

Research has been carried out on work processes thus far, but not much has been done on individual workers [8]. The technological barrier is addressed here. To date, locally, we have relied on historical data and worker's experience to guide our hazard identification and mitigation strategies. However with the available technology available, real time data can be collected, analysed and used to mitigate current hazards. The use of smart equipment to collect data on the ever changing physical environment is valuable. These can include wind speed, temperature, the likelihood of rain, pressure, noise and even data on the individual workers vital signs. The technology can also be used to monitor the performance and location of each worker. The location of each worker on site at all times is important, especially in case of accidents and other emergencies. A good performance from each worker is important to ensuring that the safety objectives are achieved. Safety should be the number one priority of each individual.

Investing in the proper administration of safety resources is also an important barrier for JHA and RA. On many occasions the client does not have safety officers on sites for the entire duration of the works. This is due to lack of resources. It is also not a requirement for the contractor to have a fulltime safety officer as well. So the onus falls on other workers to be responsible for the safety administration. This investment has a good chance of saving money in the future. With the presence of a safety representative, the JHA and RA can also be more project specific as was identified as a major barrier [5]. This is because each project is unique. 
Finally, the regulatory authorities need to be more proactive in ensuring proper compliance with the JHA and RA documents. One way can be to have ad hoc visits to construction sites and possibly warnings and fines in extreme events. As with any process, it needs to be championed. Another way is continuous professional development, this is the only way to keep abreast of the knowledge advances in this dynamic field. These authorities can facilitate regular trainings and sharing of new knowledge to the local industry.

This highlights the need for a mixture of qualitative and quantitative methods in effective administration of the JHA and RA documents.

\section{Case Study Findings}

Based on the case studies carried out on three construction sites, the following Table 3 illustrates the results obtained. On all three sites the construction manager was asked to answer the case study questions where most of the answers were unanimous. The findings of the case study validates the research.

Table 3: Case Study Results

\begin{tabular}{|l|c|c|c|}
\hline \multicolumn{1}{|c|}{ Case Study Questions } & $\begin{array}{c}\text { Case Study 1 } \\
{[14]}\end{array}$ & $\begin{array}{c}\text { Case Study 2 } \\
{[15]}\end{array}$ & $\begin{array}{c}\text { Case Study 3 } \\
{[16]}\end{array}$ \\
\hline $\begin{array}{l}\text { Was a JHA and RA prepared for the } \\
\text { works? }\end{array}$ & $\checkmark$ & $\checkmark$ & $\checkmark$ \\
\hline $\begin{array}{l}\text { Were these documents prepared on } \\
\text { the same day of the works? }\end{array}$ & $\checkmark$ & $\checkmark$ & $\checkmark$ \\
\hline $\begin{array}{l}\text { Did the construction manager or site } \\
\text { superintendent prepare these } \\
\text { documents? }\end{array}$ & $\checkmark$ & X & X \\
\hline $\begin{array}{l}\text { Was there any specific training for } \\
\text { JHA and RA preparation for the } \\
\text { person/persons preparing these } \\
\text { documents? }\end{array}$ & X & & \\
\hline $\begin{array}{l}\text { Did the JHA and RA capture site } \\
\text { specific hazards? }\end{array}$ & X & X & $\checkmark$ \\
\hline $\begin{array}{l}\text { Was there any unforeseen } \\
\text { hazard/hazards that affected either the } \\
\text { labour, material or equipment } \\
\text { resources? }\end{array}$ & $\checkmark$ & $\checkmark$ & $\checkmark$ \\
\hline $\begin{array}{l}\text { If yes, did the hazard/hazards have a } \\
\text { cost impact on the resources? }\end{array}$ & $\checkmark$ & $\checkmark$ & $\checkmark$ \\
\hline Was the resource labour or material? & $\checkmark$ & X & $\checkmark$ \\
\hline $\begin{array}{l}\text { In hindsight, was the JHA and RA } \\
\text { effectively prepared for the safe } \\
\text { execution of the works? }\end{array}$ & X & $\mathbf{X}$ & $\mathbf{X}$ \\
\hline
\end{tabular}




\section{Conclusions}

Based on the research carried out, the main barriers for implementation identified were lack of proper training specific to JHA and RA administration specific for each project, limited academic research in this field locally, limited use of technology and the reactive approach by the relevant regulatory authorities. These results show that not enough time is spent on updating the JHA and RA during the life of the project, as these documents are live documents that needs to be updated and regulated on a regular basis depending on the demands of the project.

The cost impacts that had the most influence on the hazards were labour, material and equipment respectively. Although the results were close, this is understandable as labour is generally seen as the hardest resource to manage because of the human factor.

Electricity, mechanical and body mechanics had the biggest average impact on cost respectively. It should be noted that the hazards identified in the JHA and RA were not site specific.

Locally there is doubt about the effectiveness of the JHA and RA documents for building services installation. One reason for this can be attributed to the subjective nature in the preparation and administration of these documents.

\section{References}

[1] Forteza Francisco., J., Albert Sese., and Jose M. Carretero-Gomez. 2016. "CONSTRAT. Construction Sites Risk Assessment Tools." Safety Science. http://dx.doi.org/10.1016/j.ssci.2016.07.012.

[2] Perlman., Amotz., Rafael Sacks., and Ronen Barak. 2013. "Hazard recognition and risk perception in construction." Safety Science. http://dx.doi.org/10.1016/j.ssci.2013.11.019.

[3] Fung., Ivan W.H., Vivian W.Y. Tam., Tommy Y. Lo., and Lori L.H. Lu. 2009. "Developing a Risk Assessment Model for construction safety." International Journal of Project Management. doi:10.1016/j.ijproman.2009.09.006.

[4] Taroum., Abdulmaten. 2013. "Towards a better modelling and assessment of construction risk: Insights from a literature view.”International Journal of Project Management. http://dx.doi.org/10.1016/j.ijproman.2013.03.004.

[5] Pinto., Abel., Isabel L Nunes., and Rita A Ribero. 2011. "Occupational risk assessment in construction industry - Overview and reflection.” Safety Science. doi:10.1016/j.ssci.2011.01.003. [6] Uff, John, and Desmond Thornhill. 2010. Report of the Commission of Enquiry into the Construction Sector Trinidad and Tobago.

[7] Harrington., David., Barbara Materna., Jim Vannoy., and Peter Scholz. 2009. "Conducting Effective Tailgate Trainings.” Health Promotion Practice. July 2009 Vol. 10, No. 3, 359-369 DOI: 10.1177/1524839907307885 @2009 Society for Public Health Education.

[8] Park., Jee Woong., Yong K. Cho., and Ali Khodabandelu. 2018. "Sensor-Based Safety Performance Assessment of Individual Construction Workers.” MDPI Journal - Sensors 18, 3897; doi:10.3390/s18113897.

[9] Patel., D.A., K.D. Kikami., and K.N. Jha. 2016. "Hazard Assessment Using Consistent Fuzzy Preference Relations Approach.” Journal of Construction Engineering and Management, () ASCE, ISSN 0733-9364. 
[10] Lavanya, N., and Malarvizhi. 2008. "Risk analysis and management: a vital key to effective project management.” Paper presented at PMI Global Congress 2008 - Asia Pacific, Sydney, New South Wales, Australia. Newtown Square, PA: Project Management Institute. [11] Albert., Alex., Matthew R. Hallowell., and Brian M. Kleiner. 2014. "Experimental field testing of a real-time construction hazard identification and transmission technique."

Construction Management and Economics. Vol. 32, No. 10, 1000-1016, http://dx.doi.org/10.1080/01446193.2014.929721.

[12] Karakhan., Ali., and Ola Alsaffar. 2019. "Technology's Role in Safety Management." Professional Safety. American Society of Safety Engineers.

[13] (Carter and Smith 2006)

[14] General Contractor specializing with the works applicable to the research. 2019. Interview by author October 23. Chaguanas, Trinidad and Tobago.

[15] General Contractor specializing with the works applicable to the research. 2019. Interview by author October 25. Port of Spain, Trinidad and Tobago.

[16] Client specializing with the works applicable to the research. 2019. Interview by author October 25. Port of Spain, Trinidad and Tobago.

[17] Tam, C.M., Zeng, S.X., Deng, Z.M., 2004. Identifying elements of poor construction safety management in China. Safety Science 42, 569-586.

[18] Kish, Leslie. 1965. Survey Sampling. New York: John Wiley and Sons, Inc. 